\title{
BYUNG-CHUl HAN Y LA POSITIVIZACIÓN DE LA SOCIEDAD: El SENTIDO, LA VERDAD Y LA LIBERTAD EN LA ERA DIGITAL
}

\section{BYUNG-CHUL HAN AND THE POSITIVIZATION OF SOCIETY: MEANING, TRUTH AND FREEDOM IN THE DIGITAL ERA}

\author{
CÉSAR AlCÁZAR ARELlano \\ Universidad del País Vasco \\ alac_yosoy@hotmail.com
}

\begin{abstract}
RECIBIDO: $23 / 04 / 2016$
ACEPTADO: 16/05/2016
\end{abstract}

Resumen: Presentación panorámica de la obra del filósofo coreano de la tecnología, que vive y enseña en Alemania, Byung-Chul Han como reflexión acerca del sentido, la verdad y la libertad en la era digital a partir del fenómeno de la positivización de la sociedad.

Palabras clave: Byung-Chul Han, positivización de la sociedad, era digital, verdad, libertad

\begin{abstract}
Panoramic presentation of the work of the Korean philosopher of technology living and teaching in Germany Byung-Chul Han as a reflection above meaning, truth and freedom in the digital age, from the phenomenon of the positivization of society.

Keywords: Byung-Chul Han, positivization of society, digital era, truth, freedom
\end{abstract}

En los últimos años el filósofo Byung-Chul Han se ha ganado una creciente atención en el campo de los estudios humanísticos a partir de su elaborado y controversial análisis sobre la condición humana en el mundo global y digitalizado. Desde una particular visión romántica ha abordado temas como el papel de las TIC en la reconstitución y el ejercicio del poder, las nuevas formas de dominación bajo el llamado neoliberalismo, las enfermedades neuronales como sintomatología existencial y cultural de nuestra época o la intensificación de los procesos productivos como fin último de los sistemas sociales, por citar algunos.

A la temprana edad de veintiún años, una vez terminada su formación en metalurgia y con apenas dominio del alemán, Han decidió dejar la capital de Corea del Sur, su natal Seúl, para emigrar a Alemania. En un principio no tenía ninguna intención de aproximarse a la filosofía, pues como él mismo afirma: “(...) Cuando llegué a Alemania, ni siquiera conocía el nombre de Martin Heidegger. (...) Yo quería estudiar literatura alemana. De filosofía no sabía 
nada"1. Sin embargo, años más tarde terminaría defendiendo una tesis doctoral sobre Heidegger e impartiendo clases en la Universidad de las Artes de Berlín.

\section{El cambio de paradigma}

Desafiando y reinterpretando conceptos de la sociología y la filosofía Han se lanza a hacer un análisis sobre el tipo de sociedad que pretende normar la configuración del actual sistema global. Uno de sus postulados principales afirma que el proceso de instauración y extensión de este modelo ha generado un "cambio de paradigma", cuya incidencia no se limita a los ámbitos de lo económico, lo político y lo social, sino que repercute, sobre todo, en la dimensión existencial y estética del ser humano. De esta forma, en el siglo XXI estaríamos ante la emergencia del mundo "post-inmunológico": una faceta en la que las estructuras que norman la vida de los individuos y las comunidades locales, nacionales e internacionales, ya no están constituidas por principios y relaciones dialécticas entre "un adentro y un afuera", "lo propio y lo extraño", "amigo/enemigo", "ataque/defensa", etc. La era pasada, estructurada por un "esquema inmunológico" bajo la noción relacional "negativo/positivo", ha sucumbido ante el fortalecimiento y extensión, sin límites, de una de las tendencias de esta relación: "la positividad".

"La positividad", como tendencia sistémica prevalente, se enmarca en una ontología que concibe todos los elementos de la realidad como materiales emplazables para la operatividad, el rendimiento y la maximización de la productividad económica. En consecuencia, se impone el principio positivo de lo "óptimo": aquella condición en la que los sujetos, los objetos, los fenómenos, los procesos y las relaciones cumplen con un estado de idoneidad para su disposición funcional. El imperativo de la optimización no tolera el accidente, "el desgarro del azar", "el sufrimiento", "la interrupción", la demora, lo mediato, lo lejano, lo oculto e intempestivo. A este respecto, podemos decir que la influencia onto-epistémica de Heidegger se hace patente a la hora en que Han caracteriza "la positividad" y "el imperativo de lo óptimo", sobre todo si recordamos la reflexión que el alemán hizo sobre la técnica y la sociedad modernas:

\footnotetext{
1 Arroyo, F. (22 de marzo de 2014). Aviso de derrumbe, El país, disponible en: http://cultura.elpais.com/cultura/2014/03/18/actualidad/1395166957_655811.html (consultado el 14 de febrero de 2016).
} 
El emplazar que provoca las energías de la naturaleza es un promover en un doble sentido. Promueve alumbrando y ex -poniendo. Este promover, sin embargo, está emplazado de antemano a promover otras cosas, es decir, a impulsar hacia la máxima utilización con el mínimo gasto (...) En todas partes se solicita que algo esté inmediatamente en el emplazamiento y que esté para ser solicitado para otra solicitación. $^{2}$

La otra tendencia, que según nuestro autor está siendo neutralizada, sería "la negatividad". Esta es concebida como el ámbito de "la otredad": aquella fenomenología de lo singular, eso que escapa a la lógica de la cuantificación y la linealidad del emplazamiento. "La negatividad" es lo extraño, lo desconocido e incluso lo peligroso; es lo que está fuera de nuestros límites y cuya extrañeza activa nuestros mecanismos, positivos, de defensa. "La negatividad", pues, era una de las condiciones de posibilidad para demarcar límites, deberes y fronteras; por tanto, era un elemento constitutivo del sistema "inmunológico": "La otredad es la categoría fundamental de la inmunología. Cada reacción inmunológica es una reacción frente a la otredad"3.

\section{El sujeto de rendimiento}

Desde la perspectiva de Han el "cambio de paradigma" no es sino el afianzamiento del "neoliberalismo". Mas, a pesar del cariz económico de este término, no lo abordará como categoría económica sino como fenómeno emergente y sistémico, cuyo fin último es la constante maximización de la productividad en aras del mayor beneficio. Por ello, nos dice que el "neoliberalismo" no es una "irrupción" sino una "mutación" sistémica del capitalismo ${ }^{4}$. Dejando ver que, en gran medida, esta "nueva forma de evolución" no tiene un carácter meramente contingente sino que hunde sus raíces en una tendencia socio-histórica consolidada y su respectivo correlato ontológico.

En el sistema neoliberal "las nuevas formas de producción", inmateriales e informacionales, han posibilitado el inconmensurable flujo de la "hípercomunicación" y la "híper-información". En el despliegue y funcionamiento de este dispositivo global de producción surge y opera el "sujeto de rendimiento", que no es otra cosa que el individuo "autoexplotado". Un agente atomizado que

\footnotetext{
${ }^{2}$ Heidegger, M. (1994) "La pregunta por la técnica", en M. Heidegger, Conferencias y artículos, Trad. E., Barjau, Barcelona, Ediciones del Serbal, pp. 18-19.

${ }^{3}$ Han, B.-Ch. (2012) La sociedad del cansancio, Trad. A. Saratxaga, Barcelona, Herder, p. 14.

${ }^{4}$ Han, B.-Ch. (2014) Psicopolítica, Trad. A, Bergés, Barcelona, Herder, p. 41.
} 
no se inserta ya en una relación de producción antagónica, pues para Han ya no hay, como en la época de Marx, un sujeto socio-histórico definido (burguesía p.e.) que sea el beneficiario estructural de la explotación: “(...) La autoexplotación sin clases le es totalmente extraña a Marx" ${ }^{5}$, nos dice. Desde este enfoque la sociedad es interpretada como una aglomeración de sujetos aislados, enceguecidos por la lógica del éxito y el rendimiento individuales, en la que la "otredad" no tiene ya ninguna densidad ontológica y en la que "el narcisismo" es el móvil que rige las proyecciones psico-culturales de los individuos. Debido a esto, el antes bien delimitado antagonismo verdugo/víctima y/o explotador/explotado se desdibuja en la figura del "sujeto de rendimiento", pues en su operatividad reproduce ambos roles.

Como vemos, el "sujeto de rendimiento" es una figura "posinmunológica", ya que no aparece confrontado con un opuesto externo que le permita una demarcación y, por ende, la constitución de un esquema de "ataque y defensa". De modo que, al no tener un contrario (un negativo) no tiene la posibilidad de generar una identidad socio-política (proletariado, explotados, los de abajo, etc.). En definitiva, carece de un "nosotros político". Es por ello por lo que esta nueva forma de vivir la individualidad no permite la condensación de glebas de resentidos sociales o revolucionarios, sino sólo deriva en la generación de individuos que, al no ver ajustadas sus capacidades productivas dentro de los parámetros del máximo rendimiento, se sienten "fracasados". Así mismo, el "sujeto de rendimiento" no es capaz de experimentar "la rabia" (reacción negativa con potencial transformador), sino tan sólo puede reaccionar con una "abreacción digestivo-neuronal"7 que se expresa en nuevas formas de neurosis: depresión, trastorno por déficit de atención con hiperactividad (TDAH), trastorno límite de la personalidad (TLP) o el síndrome de desgaste ocupacional (SDO), etc. Concluyendo, el "sujeto de rendimiento" es el individuo enajenado por la positivización de la producción. Es su voluntad, como expresión afirmativa

\footnotetext{
${ }^{5}$ Han, B-Ch. (2014) op. cit., p. 18.

${ }^{6}$ Uno de los síntomas y efectos del narcicismo galopante, que Han detecta en nuestra actualidad, es la paulatina extinción del deseo en las relaciones humanas. Según su enfoque, las relaciones se ven encerradas en una prisión de proyecciones en las que la figura única y rectora es el individuo proyector y el otro es diluido y reducido a mero objeto satisfactor. El genuino deseo, para Han, es el querer la singularidad del otro, aquello que no somos y que no tenemos, pero que sin embargo identificamos en la otredad. El narcisista, por el contrario, no logra ver al otro, no alcanza a identificar su particularidad; su visión está regida únicamente por sus necesidades y las relaciones son un medio para intentar darles satisfacción .Véase: Han, B.-Ch. (2014) La agonía de eros, Trad. R. Gabás, Barcelona, Herder, p. 11.

${ }^{7}$ Han, B.-Ch. (2012) La sociedad del cansancio, Trad. A. Saratxaga, Barcelona, Herder, p. 18.
} 
(positiva), la que lo integra y mantiene en la inercia del máximo rendimiento y lo sume en una neurótica impotencia.

\section{La transparencia}

En un ejercicio hermenéutico que Han hace sobre el mito platónico de $L a$ caverna nos dice que en él no se exponen dos formas distintas de conocimiento, sino "diversos modos de vida", a saber: al interior de la caverna, con fuego artificial y con técnicas representativas, se proyectan "ilusiones escénicas e imágenes y apariencias", las cuales son guiadas por una trama central que apela al ámbito del sentido. Es una dimensión estética que constituye un "mundo narrativo". Por el contrario, en la parte exterior hay una fuente generadora de "luz", el sol, que permite revelar "la verdad". Por consiguiente, tenemos dos "modos de vida", el "narrativo" y el de la "verdad", que se mueven en una relación de exclusión mutua: "La luz de la verdad despoja al mundo de su carácter narrativo"9.

Mas, a pesar de la oposición entre estos dos modos, Han deja ver que ambos están enclavados en dimensiones ontológicas que o bien orientan hacia "la verdad" o bien hacia la constante creación y transformación de sentidos. Por tanto, ambas dimensiones son demarcativas, ya que sostienen marcos referenciales, epistémicos o estéticos, que permiten constituir, a partir de la sensibilidad de la experiencia o del uso cognitivo de la razón, identidades. Es decir, ambas posibilitan la existencia de la "otredad" como aquello otro que no son o que está fuera de los límites de su ser. Esta interpretación nos permite entender por qué Han lanza su látigo critico contra la sociedad actual: nuestra realidad carece de "luz" y de narratividad, adolece por la ausencia de "verdad y de sentido", ya que se encuentra normada por el "dispositivo neoliberal" 10 de "la transparencia": (...) una irradiación sin luz, que, en lugar de esclarecer, lo penetra todo" 11 .

"El esclarecimiento" es un acto comprensivo y hermenéutico que tiene como elemento fundamental la capacidad reflexiva del ser humano. Dicho de otra manera, "el esclarecimiento" se produce en un acto reflexivo que conlleva una senda deliberativa, es un proceso decisorio determinado por el flujo polisémico

\footnotetext{
${ }^{8}$ Han, B.-Ch. (2013) La sociedad de la transparencia, Trad. R. Gabás, Barcelona, Herder, 2013, p. 74.

${ }^{9}$ Han, B.-Ch. op., cit., p. 75.

${ }^{10}$ Han, B.-Ch. Psicopolítica, Trad. A, Bergés, Barcelona, Herder, 2014, p. 21.

${ }^{11}$ Han, B.-Ch. op. cit., p. 77.
} 
de la realidad, que siempre es contextual. Por el contrario, "la transparencia" es un mecanismo de emplazamiento en el que toda aproximación cognitiva a entidades, fenómenos o relaciones se realiza con vistas a performar y optimizar sus propiedades y condiciones de cara a su utilidad en el funcionamiento del sistema neoliberal. En suma, "la transparencia" es la "desnuda" instrumentalización de "la verdad y el sentido" para un fin ajeno a su naturaleza.

Por medio de "la exhibición", "la exposición" y el desocultamiento "la transparencia" recoge y refuncionaliza todo en pos de la economía del máximo beneficio: las entidades son exhibidas en aparadores sociales, culturales, digitales, etc. Son arrebatadas de su contexto narrativo, en el cual tiene un valor propio e inconmensurable, para ser trasladadas a diversos dominios de espíritu mercantil en el que son sometidas a la maquinación de un aparato cuantificador. Proceso en el que la singularidad es subsumida bajo determinada magnitud de una métrica homogeneizadora. Es así que, en "la sociedad de la transparencia" predomina el "valor de exhibición", en apabullante detrimento del "valor cultual" 12 . Cabe aclarar que, estos dos tipos de valores no deben ser relacionados o asimilados con los valores de cambio y de uso que postuló Marx, ya que, como el propio Han señala, el "valor de exhibición" está orientado a la "producción de atención" y en él no se refleja ninguna magnitud de fuerza de trabajo y, por el contrario, el "valor cultual" es relativo a la dimensión estética y existencial de procesos simbólicos y ritos.

Así mismo, "la transparencia" es un dispositivo que instrumentaliza y exhibe a través de un "lenguaje operacionalizado", la información. Aquello que, como el mismo Han nos recuerda, Heidegger llamó el lenguaje del engranaje o del emplazamiento: "El hablar es emplazado para que corresponda a la posibilidad de encargar lo que se hace presente en todas las direcciones. El hablar así emplazado se convierte en información"13. Los ámbitos mediados por la información y sus tecnologías no permiten la expresión del sentido, el mundo narrativo está asentado en el sentimiento y no en la emoción. Las redes sociales digitales y su velocidad epidémica sólo pueden portar reacciones inmediatas no filtradas por la reflexión, su formato es emocional y su inferencia sólo es valorada desde el aspecto cuantitativo, es decir, informacional.

\footnotetext{
${ }^{12}$ Han, B.-Ch. (2013) La sociedad de la transparencia, Trad. R. Gabás, Barcelona, Herder, p. 26.

${ }^{13}$ Citado textualmente en Han, B.-Ch. op. cit., p. 77.
} 


\section{Psicopolítica y Big Data: el poder positivo y su conocimiento de dominación}

En la propuesta de Han la "mutación del capitalismo en neoliberalismo" trajo consigo una nueva forma de poder y de dominación que no se sustenta en "la negatividad" de la prohibición y la obediencia coactivas, que serían propias de la sociedad disciplinaria que analizó Foucault ${ }^{14}$. "La psicopolítica" es "un poder supremo", "un poder inteligente", que no "niega o somete la libertad sino que la explota"15. La voluntad del individuo "no es reprimida sino seducida", "es optimizada y no obstaculizada". Su especificidad ontológica consiste en que no actúa como cuerpo, ni está orientado a la dominación del mismo, sino que "se comporta como alma"16. La supremacía que sustenta se debe a su condición psíquica y positiva, pues "cuanto mayor es el poder, más silenciosamente actúa"17. "La Psicopolítica" es, pues, el poder orientado a dominar la psique humana para su emplazamiento en el sistema neoliberal. De la Biopolítica se ha pasado a "la Psicopolítica" y sendas formas obedecen a facetas distintas de la producción capitalista. La dominación y explotación de la psique es el objetivo del poder neoliberal en la era de la información y la comunicación, es la "forma de gobierno" del capitalismo posindustrial.

En el despliegue del poder psicopolítico la acumulación y gestión de información a gran escala, el Big Data, juega un papel de primer orden. Los datos acumulados, organizados y emplazados permiten configurar patrones tendenciales de conducta social que ayudan tanto a predecir fenómenos como a inducirlos. Razón por la cual, el Big Data se nos presenta como una herramienta de dominación social que accede a la profundidad de los "anhelos ocultos", los deseos y las necesidades de los individuos y permite el "psicoprograma del inconsciente" individual y colectivo.

El rol del Big data en "el neoliberalismo" es comparado por Han con el que jugó la estadística en la Ilustración, de donde resulta que estaríamos ante una "segunda Ilustración"18. Tanto en la primera como en la segunda se habría cometido el mismo error: arrojar el ser social a la lógica de la conmensurabilidad y su presunta predictibilidad en pos de la dominación y el máximo beneficio.

\footnotetext{
${ }^{14}$ Han dedica un capítulo completo de su Psicopolítica al concepto de Biopolítica y su dimensión social, la sociedad disciplinaria, de Foucault, para exponer un análisis sobre la inefectividad epistémica de ese corpus teórico a la hora de abordar las nuevas formas de dominación del neoliberalismo. Véase: Han, B.-Ch. (2014) Psicopolítica, Trad. A. Bergés, Barcelona, Herder, pp. 3546.

${ }^{15}$ Han, B.-Ch. op. cit., p. 29.

${ }^{16}$ Han, B.-Ch. op. cit., p. 33.

${ }^{17}$ Han, B.-Ch. op. cit., p. 27.

${ }^{18}$ Han, B.-Ch. op. cit., pp. 88-89.
} 
Ante esto, el autor nos advierte: "El medio de la primera ilustración es la razón. Pero en nombre de la razón se reprimieron la imaginación, la corporalidad y el deseo. En virtud de la dialéctica fatal de la ilustración, esta acaba convirtiéndose en barbarie. La misma dialéctica amenaza a la segunda Ilustración, que apela a la información, los datos y la transparencia. La segunda Ilustración genera una nueva forma de violencia." $"$.

En este diagnóstico, la barbarie, como posible horizonte de la era neoliberal, no parece adscribirse a una proyección apocalíptica sobre el final de la humanidad, sino a un futuro de insensatez; a la idea de una era "anestética", en cuyo seno ni siquiera tendría lugar la problemática moralidad punitiva del apocalipsis bíblico. Simplemente la constante deconstrucción de sentidos, individual y colectiva, perecería en la infinita "barbarie de los datos".

\section{El panóptico digital}

La figura panóptica, que fungió como uno de los conceptos centrales para analizar la sociedad disciplinaria, le sirve a Han para analizar la evolución de las formas de vigilancia y control hasta nuestra época: El panóptico de Bentham y el panoptismo conceptual foucaultiano exponen un topos central desde el cual se ejecutaba la acción de vigilancia y control sobre los presos, los cuales estaban incomunicados entre sí por celdas. Teniendo plena consciencia de su falta de libertad eran condenados al aislamiento y la soledad. De esto se infiere que, el panóptico clásico estaba imbricado en una sociedad inmunológica constituida por la dialéctica entre "la positividad" y "la negatividad", en ella los límites de "el adentro y el afuera" y del controlador y el controlado estaban bien demarcados.

Por el contrario, en la era de "la transparencia" y el "poder psicopolítico" el panóptico se ha positivizado, es digital. Las redes sociales en internet y la web 3.0 son las estructuras de vigilancia y control positivas: los presos acceden voluntariamente a su prisión al integrarse en las diversas redes sociales, al verter libremente todo sus datos en los repositorios del Big data y al exhibirse por medio de imágenes y diálogos. En esta nueva prisión los presos se sienten libres y se vigilan unos a otros, dejando inoperativa la subjetividad central que vigilaba en el panóptico disciplinario. De manera que, se abandona "la negatividad" de la incomunicación y el aislamiento benthamianos y se impulsa y explota la comunicación entre individuos. Todas estas características del panóptico digital

\footnotetext{
${ }^{19}$ Han, B.-Ch. op. cit., p. 89.
} 
están sustentadas, según Han, en virtudes concebidas socialmente como positivas: la voluntad, la libertad y la comunicación. En síntesis, a través de una "vigilancia sin vigilancia" lo social es emplazado.

\section{Libertad paradójica}

Uno de los efectos más críticos que ha generado el "cambio de paradigma" es "la crisis de la libertad". Para Han la libertad es tan sólo un "entreacto" "un tránsito histórico") que va de una etapa de opresión a otra de mayor libertad. A su vez, esta nueva etapa de libertad esta siempre orientada a convertirse en una nueva etapa de opresión. De ahí que, pareciera que el ser humano está condenado a una irresoluble dialéctica histórica de opresión y libertad: "Así, a la liberación sigue una nueva sumisión. Este es el destino del sujeto, que literalmente significa estar sometido" 20 .

Sin embargo, Han cree que la opresión positiva que opera en la era neoliberal es más peligrosa y efectiva. Y es que, en "la sociedad de la transparencia", "el sujeto de rendimiento" se asume como un "proyecto libre" que, al no percibir una entidad externa y opuesta que le obligue a construir mecanismos de defensa, considera que todo su obrar es una "acción libre"; es decir, los individuos en "el neoliberalismo" viven su "autoexplotación" y "exhibición" con un "sentimiento de libertad", quedando inermes ante una coacción interna y propia que, al estar enraizada en la subjetividad, es difícil que se aperciban de ella. Es así como, la "libertad positiva" performa la materia prima de la "autoexplotación", induciéndola con los mecanismos digitales del insospechado "poder psicopolítico". Por ello, la opresión positiva neoliberal no generaría las condiciones de posibilidad para una lucha por la liberación, ya que los individuos dominados creen que la libertad es la condición principal de su ser productivo.

En suma, la sociedad actual que nos describe Han es una sociedad que asume la opresión como libertad (libertad paradójica); que se exhibe sin mayor sentido estético (sociedad pornográfica) y que por ello sufre la irreparable pérdida de la gracia (obscena). Una sociedad en la que la verdad no demarca ni orienta, porque ya no hay conocimiento que la busque, sino sólo gestión informacional que la subsume y emplaza. Desde esta perspectiva asistimos, pues, a una "desnarrativización" de la vida humana. Siendo así que, si Lyotard nos decía a finales de los setentas que los grandes metarrelatos se habían diluido como paradigmas ontológicos de justificación moderna, emergiendo por ello una

\footnotetext{
${ }^{20}$ Han, B.-Ch. (2014) Psicopolítica, Trad. A. Bergés, Barcelona, Herder, p. 11.
} 
constelación caleidoscópica (totalidad fragmentaria) de contextos polisémicos con narratividades locales y nunca universalizables, Han nos dice, a inicios del siglo XXI, que el mundo se "desnarrativiza". La sociedad cae en una deriva "anestética". La total pérdida del sentido es la seña de la sociedad neoliberal.

\section{Pluralidad, poder y positividad en la era digital}

Las ideas principales de la propuesta haniana suponen un fértil material para el actual debate sobre el rol de Internet y las TIC en las diversas dinámicas y relaciones que atraviesan, determinan y constituyen el fenómeno del poder y/o los poderes en algunas sociedades del siglo XXI. En este sentido, diremos que el diagnóstico que Han hace sobre ciertas prácticas y tendencias en Internet, impulsadas por lo que él llama el "poder psicopolítico", constituye una lúcida descripción de algunos de los riesgos de enajenación psico-cultural y éticopolítica que nos acechan. Baste como ejemplo, el avasallante "valor de exhibición" impulsado a través de un modelo de individualidad narcisista que se expresa, sobre todo, en las redes sociales y que es coherente con las dinámicas de competitividad individual que la economía de mercado necesita o la peligrosa evanescencia de los límites de "la transparencia" en los asuntos públicos, que tiende a difuminar las fronteras entre un asunto de genuino interés público y la morbosidad de un espectáculo mediático.

Ahora bien, a pesar de la certeza de estas advertencias, consideramos que el arrojamiento de un manto conceptual, "la positividad", sobre la totalidad del fenómeno que supone la red digital en el mundo global no parece hacer justicia a la amplia diversidad y complejidad de los espacios, agentes, procesos y acciones que han ido emergiendo en él. Ya que, por más que el neoliberalismo sea un proyecto con un fuerte sesgo productivista y utilitarista, que pugna por consolidarse como estructura regidora del flujo productivo y comunicativo en el mundo, no significa que no encuentre ningún tipo de resistencia (negatividad) ahí donde busque asentarse, ni mucho menos que la red sea una pista "lisa" en la cual circulen, sin mayor oposición ni obstáculo, contenidos unívocos orientados exclusivamente a la dominación social. Por el contrario, la historia de las últimas décadas nos sugiere que a pesar de que las contradicciones sistémicas han mutado en forma, contenido y magnitud, no han desaparecido y que la red digital y la creciente socialización de las TIC han hecho emerger agentes, ámbitos y acciones que son difíciles de caracterizar bajo modelos y conceptos exclusivamente positivos. 
En todo caso creemos que, como bien lo destaca Javier Echeverría, en la red confluyen una pluralidad de agentes étnicos, empresariales, políticos, etc., que comportan diferentes orígenes, objetivos y valores y cuya interacción supone uno de los mayores retos a los que se enfrenta nuestra actualidad:

La globalización implica la convivencia en un mismo espacio digital (Internet, por ejemplo) de culturas y lenguas diferentes, así como de distintos modos de concebir el mundo (...) en el tercer entorno no sólo se convive con personas de la misma cultura, y con sistemas de valores similares, sino con personas, empresas, instituciones y acontecimientos que actúan en base a una gran multiplicidad de valores. El pluralismo axiológico de la sociedad tecnológica es mucho mayor que el de los Estados/Nación de la modernidad, lo cual incide en la convivencia, y por ende en la vida. ${ }^{21}$

Esta pluralidad que menciona Echeverría no es una armoniosa totalidad convenida previamente bajo principios democráticos que promocionen la diversidad, sino un fenómeno global voraginoso y variable que está impulsado por necesidades propias y específicas de los agentes (ejércitos, gobiernos, ciudadanos, grupos políticos, insurgentes, terroristas, empresas, universidades, etc.). Lo cual los lleva a incurrir, en algunos casos de manera espontánea, en la red global para interactuar con otros agentes de naturaleza distinta y en algunas casos opuesta. Es por esto que, encontramos una red digital con flujos multidireccionales y, por ende, plurívocos, que conlleva el desarrollo de relaciones complejas y también contradictorias.

Uno de los ámbitos que más puede reflejar la complejidad interactiva, cuando no problemática (negativa), de la pluralidad de agentes en la red y que puede contrastar con la hipótesis de la dominación "psicopolítica" de Byung Chul Han es, precisamente, el político: la relación actual entre la ciudadanía y el estado parece estar sufriendo algunos cambios debido al uso y socialización de las TIC e Internet, ya que han posibilitado que la capacidad de control y vigilancia, históricamente en manos de los estados, se haya vuelto accesible para sujetos civiles, individuales y colectivos. De ahí que, algunos autores hayan analizando los cambios en el equilibrio de esta relación a partir del uso social de las TIC y la red, a este respecto Daniel Innerarity nos dice:

(...) el reequilibrio que se está produciendo actualmente tiene que ver con el hecho de que haya aumentado la supervisión ciudadana sobre el poder y las

\footnotetext{
${ }^{21}$ Echeverría, J. (2015) "Ética y racionalidad tecnológica a partir de Ramón Queraltó", Argumentos de razón técnica, $\mathrm{n}^{\circ} 18$, p. 28.
} 
posibilidades tecnológicas de llevarlo a cabo. Lo que tenemos es una suerte de "panoptismo cívico" que ha reinvertido el ejercicio de la disciplina. El poder es más sujeto pasivo que activo de observación y los ciudadanos han pasado de ser meros espectadores a celosos vigilantes. ${ }^{22}$

Manuel Castells va más allá al asegurar que la red digital, y por ende las TIC, son una condición de posibilidad para que los sujetos sociales ejerzan su autonomía y libertad de cara al estado en la sociedad red:

La autonomía se refiere a la capacidad de un actor social para convertirse en sujeto definiendo su acción alrededor de proyectos construidos al margen de las instituciones de la sociedad, de acuerdo con los valores e intereses del actor social (...) Sostengo que Internet proporciona la plataforma de comunicación organizativa para traducir la cultura de la libertad en la práctica de la autonomía. Eso es así porque la tecnología de Internet representa la cultura de la libertad, como se demuestra en el registro histórico de su desarrollo. $^{23}$

Concluyendo, creemos que aunque "la positividad", como poder y tendencia sistémica, es un fenómeno con un amplio potencial de dominio, la naturaleza misma de las TIC e Internet han posibilitado nuevos espacios y herramientas interactivas que se han convertido en recursos comunicacionales y organizativos para individuos y grupos de la sociedad civil que buscan transformaciones sociales. Por ello, no nos parece aventurado decir que la "autonomía comunicacional de masas" que identificó Castells y el "panoptismo cívico" del que habla Innerarity pueden ser concebidos como dos rasgos de negatividad contrarios al "poder psicopolítico", ya que, en algunos contextos, han supuesto prácticas contestatarias que llegan a obstaculizar el desarrollo óptimo del sistema neoliberal.

En todo caso, creemos que "la positividad" no goza de una plenitud omnisciente en el mundo globalizado, ya que, sin perjuicio de que es una estructura prevalente que no hay que dejar de observar, sigue encontrando obstáculos y resistencias que, paradójicamente, son posibilitados por las propiedades constitutivas de los medios tecnocientíficos que crea y usa para resguardar su permanencia y ampliar su reproducción.

Por tanto, mantendremos, dentro de las posibilidades críticas y argumentativas que nos permite este documento, que el uso actual de las TIC e

\footnotetext{
${ }^{22}$ Innerarity, D. (2013) Un mundo de todos y de nadie, Barcelona, Paidós, p. 89.

${ }^{23}$ Castells, M. (2012) Redes de indignación y esperanza, Madrid, Alianza Editorial, p. 220.
} 
Internet presenta una condición de ambivalencia respecto a su papel en las relaciones y dinámicas sociales del poder, ya que por una parte pueden ser instrumentos efectivos de control y dominación social y por otro pueden ser dispositivos procedimentales que posibiliten procesos emancipatorios. Sólo una aproximación situada, contextual, nos permitirá dar razón de esta condición, lo cual nos permite alejarnos de generalizaciones esencialistas en un mundo de veloz y epidémica variabilidad.

\section{Bibliografía}

Castells, M. (2012) Redes de indignación y esperanza, Madrid, Alianza Editorial.

Han, B.-Ch. (2012) La sociedad del cansancio, Trad. A. Saratxaga, Barcelona, Herder.

Han, B.-Ch. (2013) La sociedad de la transparencia, Trad. R. Gabás, Barcelona, Herder.

Han, B-Ch. (2014) Psicopolítica, Trad. A, Bergés, Barcelona, Herder.

Heidegger, M. (1994) "La pregunta por la técnica", en Martin Heidegger conferencias y artículos, Trad. E. Barjau, Barcelona, Ediciones del Serbal.

Echeverría, J. (2015) "Ética y racionalidad tecnológica a partir de Ramón Queraltó", Argumentos de razón técnica, $\mathrm{n}^{\circ} 18$.

Innerarity, D. (2013) Un mundo de todos y de nadie, Barcelona, Paidós, 2013. 



\section{SECCIÓN BIBLIOGRÁFICA / REVIEWS}


